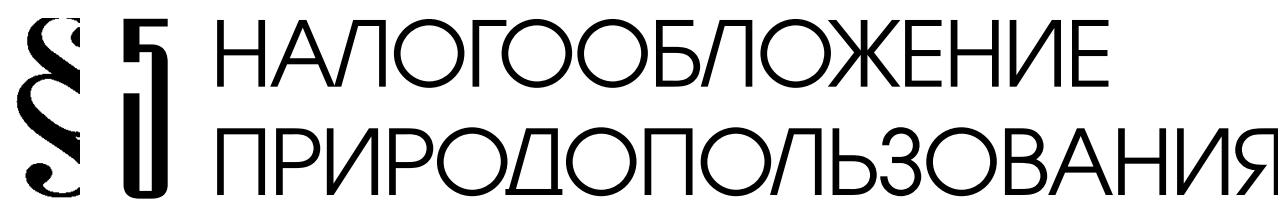

М.С. Ермакова

\section{ПОРЯДОК ОТРАЖЕНИЯ НАЛОГА НА ПРИБЫЛЬ В УЧЕТНОЙ ПОЛИТИКЕ АГРОХОЛДИНГА}

\begin{abstract}
Аннотация: В статье дано определение арохолдинга, как сложной организационной структуры, каждый участник которой выполняет свои специфические функции и задачи, направленные на поддержание целостного производственно-финансового цикла, увеличения совокупной прибыли и повышения общего благосостояния организации. В статье расскрыты особенности налогообложения компаний агрохолдинга, подразумевающие, что в качестве налогоплательщика должен выступать каждый участник холдингового объединения самостоятельно; головная компания выступает и как отдельный плательщик налогов и сборов по деятельности своей компании, и, одновременно, регулирует процесс налогообложения; головная компания и дочерние (зависимые) общества несут взаимную ответственность за неуплату налогов. Дано определение учетной политики для целей налогообложения агрохолдинга. Приведены основные элементы учетной политики агрохолдинга по налогу на прибыль. Определены льготные ставки по налогу на прибыль для сельскохозяйственных предприятий и распределение сумм налога между бюджетами. Определены приимущества и недостатки применения общего налогового режима и специальных режимов налогообложения.
\end{abstract}

Ключевые слова: единый сельскохозяйственный налог, организация, налоговый учет, налоги, учетная политика, агрохолдинг, налог на прибыль, налоговый режим, бухгалтерский учет, порядок.

A грохолдинг представляет собой сложную организационную структуру, каждый участник которой выполняет свои специфические функции и задачи, направленные на поддержание целостного производственно-финансового цикла, увеличения совокупной прибыли и повышения общего благосостояния организации.

Налогообложение сельскохозяйственных организаций имеет отличительные признаки, обусловленные особенностями производства продукции: сезонность, зависимость от климатических условий, зональная специфика, биологические факторы, рискованность ведения сельского хозяйства и др. ${ }^{1}$ Данные особенности оказывают влияние на финансовые результаты в отрасли и как следствие на налогообложения агрохолдинга.

Налогообложение агрохолдингов, несмотря на то, что налоговое законодательство не рассматривает группу компаний как единого налогоплательщика, имеет ряд особенностей:

- в качестве налогоплательщика выступает каждый участник холдингового объединения самостоятельно;

\footnotetext{
Татарников К.М. «Развитие налогообложения агрохолдингов: проблемы и их решение/ Известия Иркутской государственной экономической академии. 2008. № 2. С. 26-28.
} 
- $\quad$ головная компания выступает и как отдельный плательщик налогов и сборов по деятельности своей компании, и, одновременно, регулирует процесс налогообложения;

- головная компания и дочерние (зависимые) общества несут взаимную ответственность за неуплату налогов.

Вопросы налогообложения должны быть прописаны вучетной политики для целей налогообложенияагрохолдинга.

Учетная политика для целей налогообложения - выбранная налогоплательщиком совокупность допускаемых Налоговым кодексом способов (методов) определения доходов и (или) расходов, их признания, оценки и распределения, а также учета иных необходимых для целей налогообложения показателей финансовохозяйственной деятельности налогоплательщика. ${ }^{2}$

В отношении учетной политики для целей налогообложения в настоящее время какого-либо нормативного документа, регламентирующего основы ее формирования, не существует, есть только отдельные положения Налогового кодекса Российской Федерации, подлежащие отражению в этом документе. Например, по налогу на добавленную стоимость и по налогу на прибыль организаций. Поэтому вопросы формирования учетной политики в целях налогообложения головная организация агрохолдинга разрабатывает самостоятельно.

В настоящее время сельскохозяйственные производители имеют возможность применять общий режим налогообложения или единый сельскохозяйственный налог (ЕСHX).

2 Налоговый кодекс Российской Федерации. Часть первая / Под общей ред. В.И. Слома.- М.: Статут.
Если компании агрохолдинга используют общий режим налогообложения, то они признаются плательщиками налога на прибыль. Порядок исчисления и уплаты данного налога установлен главой 25 «Налог на прибыль организаций» НК РФ.

Компании агрохолдинга исчисляют налоговую базу по налогу на прибыль по итогам каждого отчетного (налогового) периода на основе данных налогового учета. Формы налоговых регистров утверждаются головной компанией в приложении к разделу учетной политики агрохолдинга для целей налогообложения. Кроме того, для компаний совмещающих общую систему налогообложения с системой налогообложения в виде единого налога на вмененный доход должна закрепляться методика раздельного учета. Отсутствие у таких компаний раздельного учета может иметь серьезные последствия (пп. 14 п. 1 ст. 251 Налогового кодекса Российской Федерации).

В учетной политике для целей налогового учета агрохолдинга по налогу на прибыль устанавливаются элементы, касающиеся как порядка исчисления налога на прибыль, так и способа уплаты авансовых платежей по налогу. Все элементы по налогу на прибыль, отражаемые в учетной политике, представлены в таблице 1.

Для тех сельскохозяйственных предприятий, которые не перешли на уплату единого сельскохозяйственного налога $(\mathrm{ECXH)и} \mathrm{являются} \mathrm{плательщиками} \mathrm{налога}$ на прибыль, введены определённые льготные ставки по налогу на прибыль.

В таблице 2 приведены ставки налога на прибыль и распределение сумм налога между бюджетами на 2004-2015 годы:

Льготная ставка 0\% применяется сельскохозяйственными товаропроизводителями только в том случае, если производи- 
DOI: $10.7256 / 1812-8688.2014 .3 .9618$

При цитировании этой статьи сноска на doi обязательна

Налоги и налогообложение - №3(117)• 2014

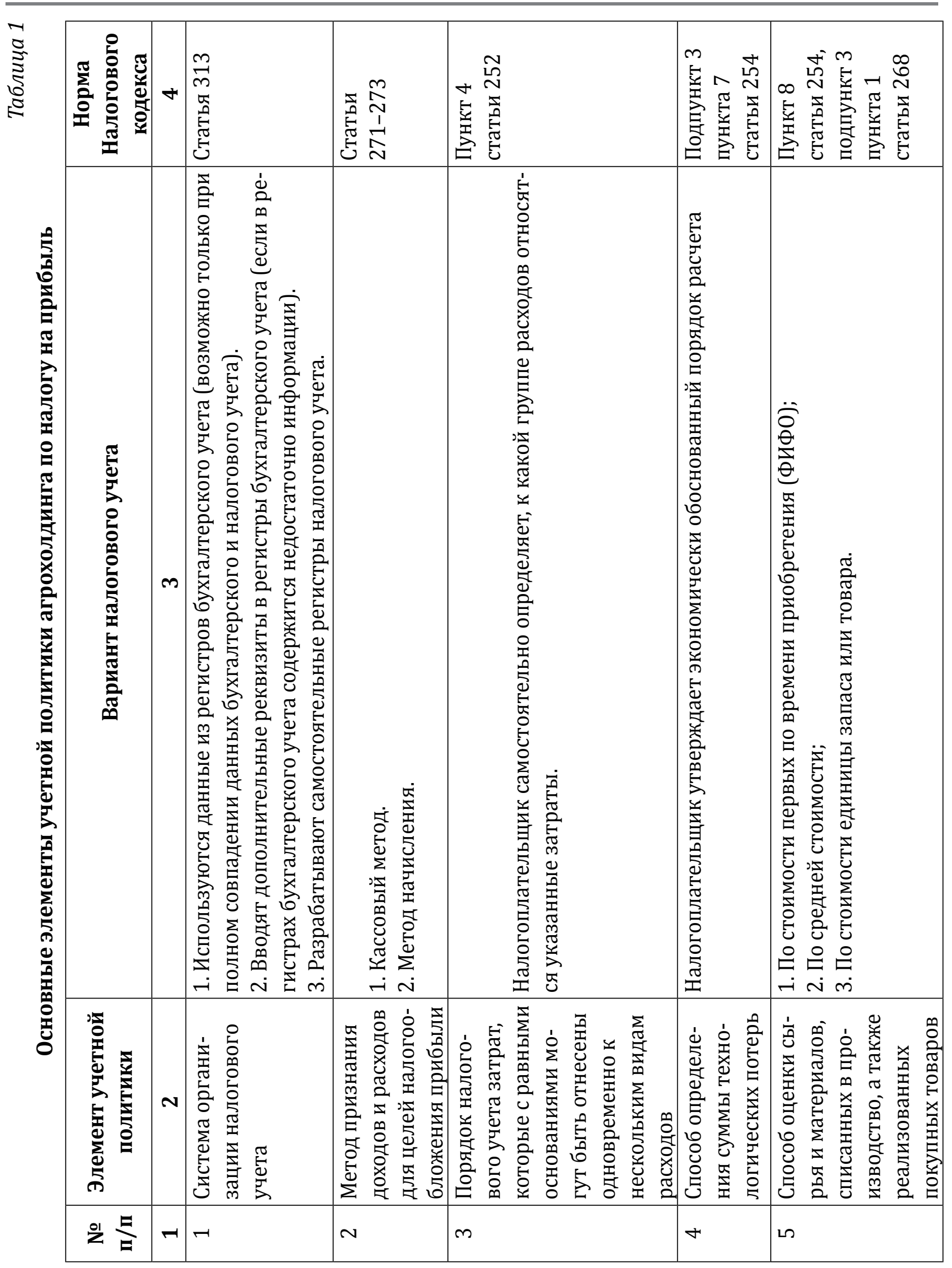


DOI: $10.7256 / 1812-8688.2014 .3 .9618$

При цитировании этой статьи сноска на doi обязательна

Налогообложение природопользования

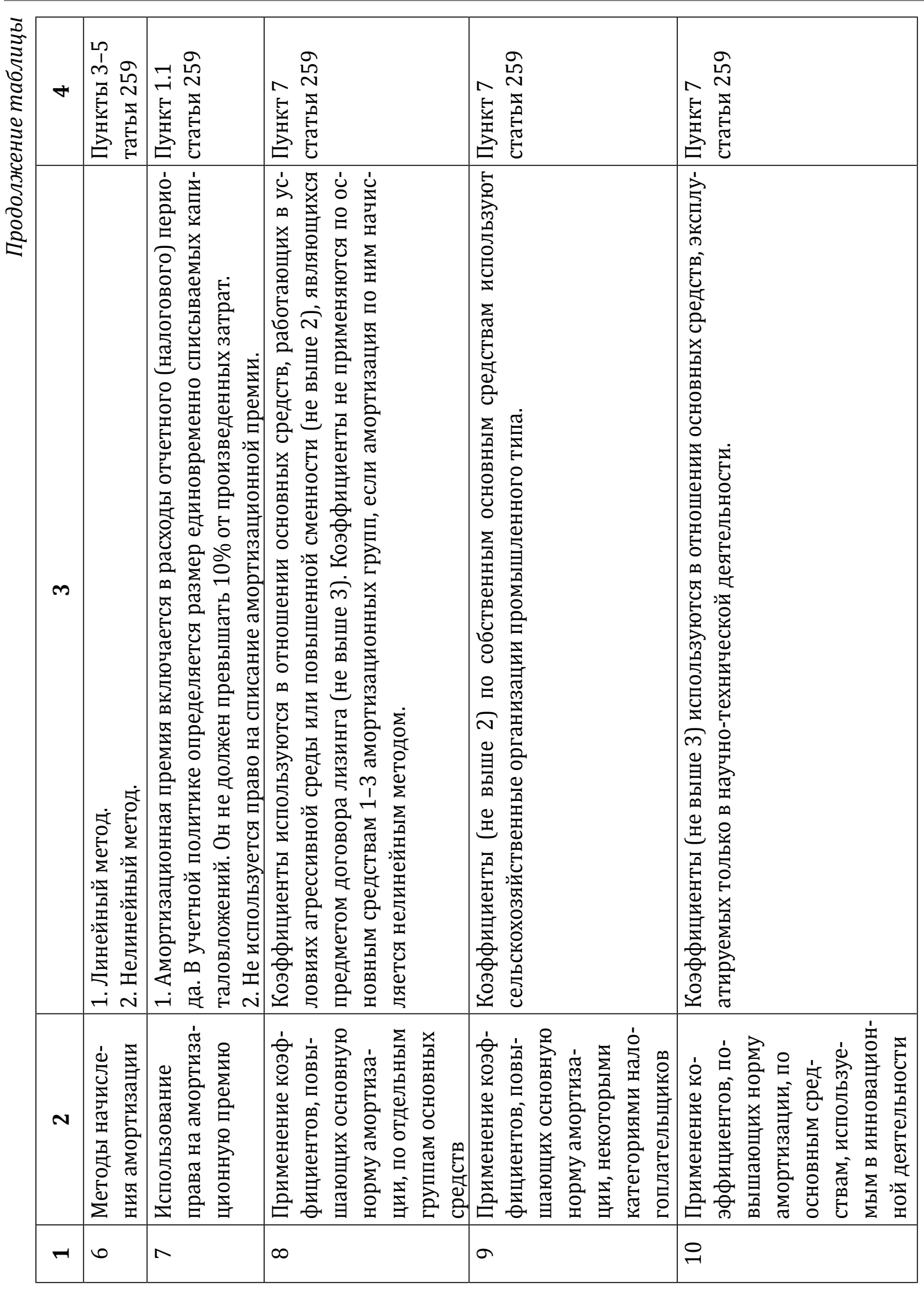


DOI: 10.7256/1812-8688.2014.3.9618

При цитировании этой статьи сноска на doi обязательна

Налоги и налогообложение - №3(117)• 2014

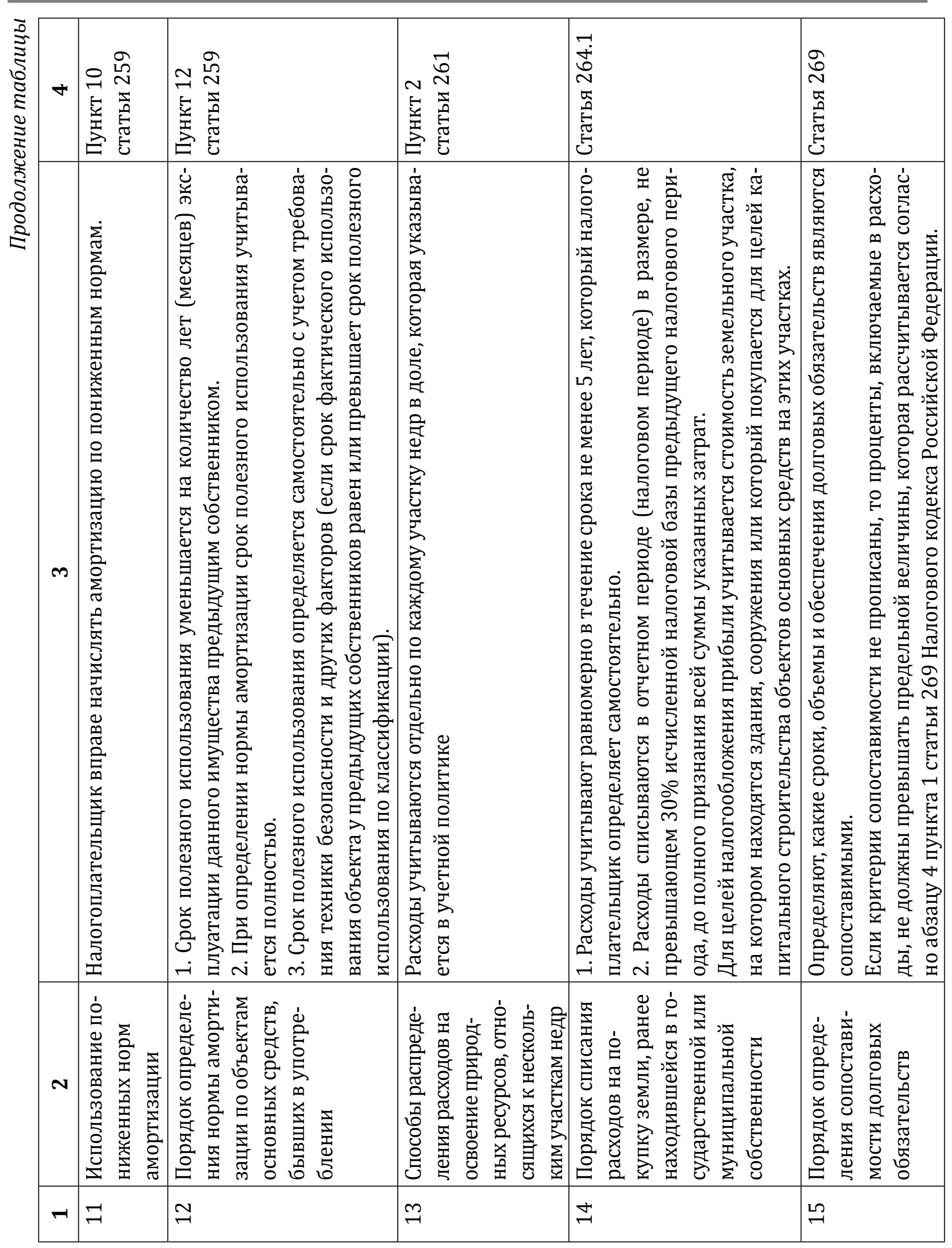


DOI: $10.7256 / 1812-8688.2014 .3 .9618$

При цитировании этой статьи сноска на doi обязательна

Налогообложение природопользования

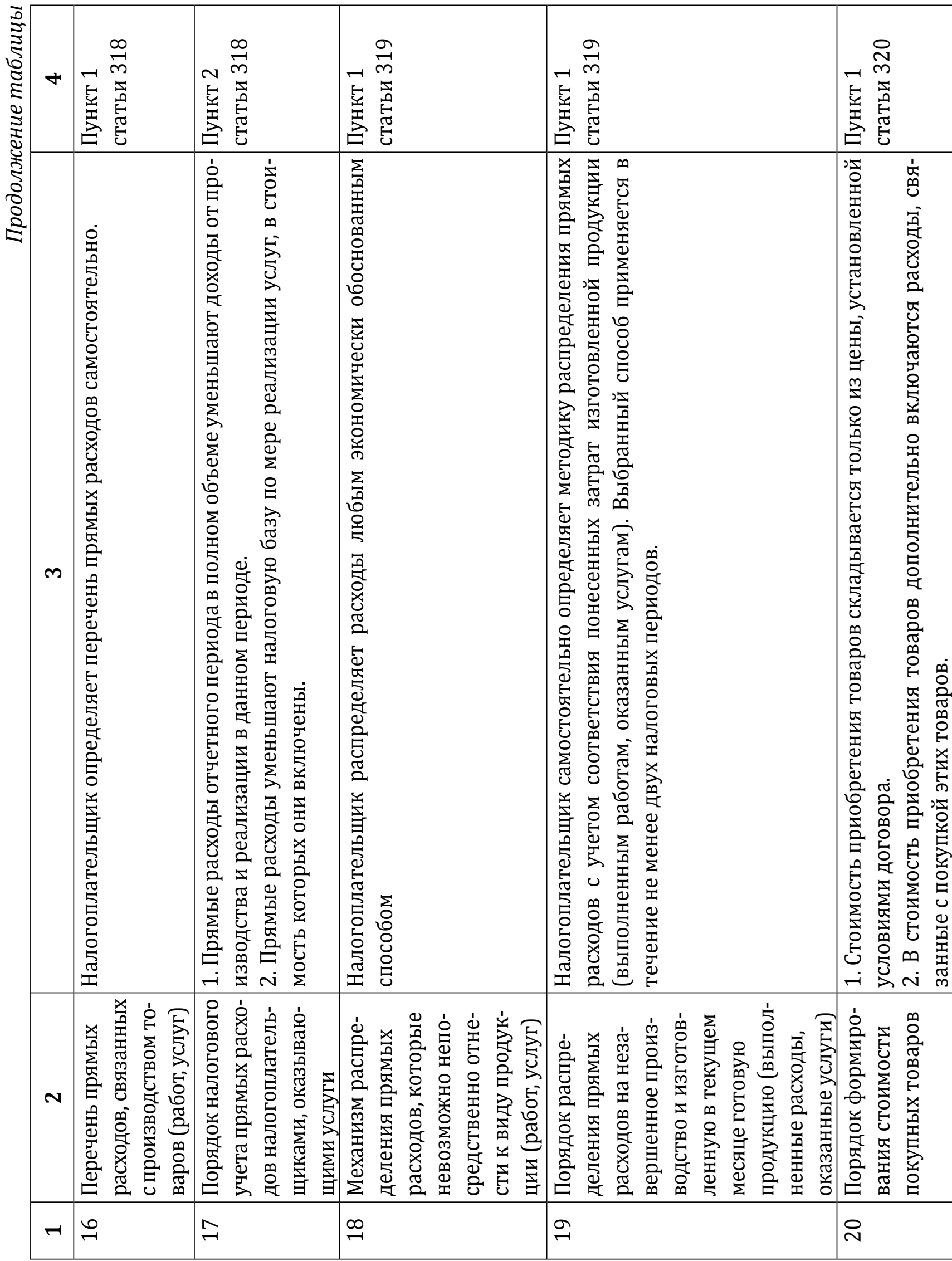


DOI: $10.7256 / 1812-8688.2014 .3 .9618$

При цитировании этой статьи сноска на doi обязательна

Налоги и налогообложение - №3(117) • 2014

Таблица 2

Льготные ставки по налогу на прибыль для сельскохозяйственных предприятий и распределение сумм налога между бюджетами на 2004-2015 годы:

\begin{tabular}{|c|c|c|c|}
\hline \multirow{2}{*}{ Годы } & \multirow{2}{*}{$\begin{array}{c}\text { Ставка } \\
\text { налога }\end{array}$} & \multicolumn{2}{|c|}{$\begin{array}{c}\text { Распределение суммы налога на прибыль, исчисленной } \\
\text { по налоговой ставке, между бюджетами Российской Федерации }\end{array}$} \\
\cline { 3 - 4 } & & $0 \%$ & $\begin{array}{c}\text { Бюджеты субъектов Российской } \\
\text { Федерации, местные бюджеты }\end{array}$ \\
\hline $2004-2007$ & $0 \%$ & $1 \%$ & $0 \%$ \\
\hline $2008-2009$ & $6 \%$ & $2 \%$ & $5 \%$ \\
\hline $2010-2011$ & $12 \%$ & $3 \%$ & $10 \%$ \\
\hline $2012-2014$ & $18 \%$ & $6 \%$ & $15 \%$ \\
\hline С 2015 & $24 \%$ & & $18 \%$ \\
\hline
\end{tabular}

тель самостоятельно нес бремя расходов, связанных с переработкой продукции, и осуществлял ее собственными силами без привлечения к процессу переработки третьих лиц.

В случае если компания агрохолдинга сельскохозяйственный товаропроизводитель передает сельскохозяйственную продукцию в переработку другой компании агрохолдинга или сторонней организации на давальческих началах и в дальнейшем ее реализует, то прибыль, полученная от реализации этой продукции облагается налогом на прибыль в порядке, предусмотренном ст. 284 Налогового кодекса Российской Федерации по ставке $20 \%$.

Таким образом, плательщиками налога на прибыль организаций могут являться и непосредственно сельскохозяйственные товаропроизводители, и компании агрохолдинга, осуществляющие переработку, хранение и реализацию продукции.

Как было сказано, компании агрохолдинга имеют возможность применять либо общий режим налогообложения либо единый сельскохозяйственный налог (ЕСHX).

Учитывая, что по налогу на прибыль сельскохозяйственные организации имеют льготы, а НДС, ЕСН и налог на имуще- ство составляют основную часть абсолютной налоговой нагрузки предприятия, освобождение от уплаты этих налогов дает предприятиям значительную сумму налоговой экономии, что, безусловно, является положительным моментом. Однако, у применения специального налогового режима есть и отрицательные стороны, такие как:

- трудности со сбытом готовой продукции, поскольку большая часть покупателей является плательщиками НДС;

- отсутствие возможности отразить в бухгалтерской и налоговойотчетности суммы налоговых вычетов по НДС, не учтенных до перехода на уплату ЕСХH;

- уменьшение рентабельности предприятия, так как объектом налогообложения являются доходы, уменьшенные на величины расходов;

- снижение конкурентоспособности продукции в результате повышения ее себестоимости и соответственно отпускных цен.

Поэтому мы рекомендуем эффективно функционирующим предприятиям агрохолдинга использовать общий режим налогообложения, так как он более целесообразен как с налоговой так и с финансовой точки зрения. Увеличение налоговой на- 
грузки вызывает у сельскохозяйственных предприятий улучшение финансовых результатов деятельности.

Применяя общую систему налогообложения, предприятия агрохолдинга имеют преимущество для расширения собственного источника финансирования, а от увеличения налоговых выплат врегиональный и местный бюджеты будет зависеть развитие сельских территорий. ${ }^{3}$

\section{Библиография:}

1. Катаев В.И., Сасина А.В. Инновационный взгляд на системы налогообложения в сельском хозяйстве/Никоновские чтения. 2009. №14. С 274-275.

2. Налоговый кодекс Российской Федерации. Часть первая/Под общей ред. В.И. Слома.М.: Статут.

3. Татарников К.М. «Развитие налогообложения агрохолдингов: проблемы и их решение/ Известия Иркутской государственной экономической академии. 2008. № 2. C. 26-28.

4. Ермакова М.С. Особенности формирования учетной политики для целей налогообложения агрохолдинга // NB: Финансовое право и управление. - 2013. — 2. C. 77-105. URL: http://www.e-notabene.ru/flc/article_778.html

\section{References:}

1. Kataev V.I., Sasina A.V. Innovatsionnyi vzglyad na sistemy nalogooblozheniya v sel'skom khozyaistve/Nikonovskie chteniya. 2009. №14. S 274-275.

2. Nalogovyi kodeks Rossiiskoi Federatsii. Chast' pervaya/Pod obshchei red. V.I. Sloma. - M.: Statut.

3. Tatarnikov K.M. «Razvitie nalogooblozheniya agrokholdingov: problemy i ikh reshenie/ Izvestiya Irkutskoi gosudarstvennoi ekonomicheskoi akademii. 2008. № 2. S. 26-28.

4. Ermakova M.S. Osobennosti formirovaniya uchetnoi politiki dlya tselei nalogooblozheniya agrokholdinga // NB: Finansovoe pravo i upravlenie. - 2013. - 2. - C. 77-105. URL: http://www.e-notabene.ru/flc/article_778.html

\footnotetext{
3 Катаев В.И., Сасина А.В. Инновационный взгляд на системы налогообложения в сельском хозяйстве/ Никоновские чтения. 2009. №14. С 274-275.
} 